
Cambridge University Press, Cambridge, UK.

\author{
$\underline{\text { Lisen Schultz }}^{1}$
}

During the last few decades, there have been many attempts within science and policy to simultaneously alleviate poverty and conserve the environment. The endeavor of combining conservation and development has resulted in a range of concepts, theories, and projects, such as Integrated Conservation and Development, Community-based Natural Resource Management, Ecosystem Approaches, and Landscape Management, to mention a few. But, in spite of careful planning, abundant resources, and the best intentions, many projects have failed to meet either or both goals. It is time to evaluate the lessons learned and find another way forward.

The Science of Sustainable Development is an ambitious contribution to this effort. Focusing on integrated natural resource management, it summarizes theories on social-ecological systems, as well as experiences "on the ground". Written by two highly experienced researchers in the field, it is a promising volume. Jeffrey Sayer has run several conservation and natural resource management programs in poverty-stricken areas, and founded the Center for International Forestry Research (CIFOR), Indonesia; Bruce Campbell is currently director of the Forests and Livelihoods program at CIFOR, and has worked in conservation and development in southern Africa for 20 years.

This book of 288 pages does indeed comprise an impressive collection of real-world observations, as well as insightful syntheses of current theory. It honestly recognizes the costs of moving from controlled laboratory experiments to integrated development projects, including investments in trust-building and understanding between different disciplines and stakeholders. However, it also convincingly argues that integration is necessary, and shows how the dual goals of conservation and poverty relief can be achieved together, specifically addressing the role of science in this endeavor. The reader is presented with some key concepts, theories, and tools of integrated natural resource management (e.g., adaptive capacity, institutional change, and multi-scale analysis), as well as detailed case studies from poverty-stricken areas of the world, including examples of both success and failure.

In Part 1, the authors introduce the issue, with the claim that researchers involved in unsuccessful conservation and development have either been too reductionist to capture reality, or have tried to embrace "everything" instead of focusing on the stakeholders and processes that matter. Furthermore, these researchers have overused expensive external expertise and neglected local knowledge. The authors propose that the time has come for a science that acknowledges and analyzes complexity, uses active research, considers effects at several scales, and uses models for understanding and negotiations. This practice includes reorienting the objective of natural resource management towards improved adaptive capacity and system resilience by focusing on sustainable development and adaptation instead of sustainable yields. It also includes giving attention to more than technology by involving institutional change and decision-making processes. Furthermore, it adds weight to action approaches and process facilitation. I find all of these recommendations well grounded in experiences and theories, and highly relevant. The authors also point out that we can not all be process facilitators, and that ecologists, engineers, and other specialists will still play important roles. However, I felt that the book could have been strengthened by a deeper discussion of the balance between leadership and 
facilitation because recent research shows that a common vision and shared direction is crucial for successful management (Folke et al. 2005).

In Part 2, the authors provide detailed descriptions of three cases where research and development projects have continued over many years: farming systems and micro-catchment management in Chivi, Zimbabwe, management of forest margins in Indonesian Borneo, and hillside agriculture in the Andes of South America. The Zimbabwe case illustrates how projects in reality can become difficult, even with the best intentions, competence, and planning. The Borneo case illustrates the benefits of an initial exploratory approach and describes a method of working with several disciplines and knowledge systems. It emphasizes the importance of flexibility and learning when dealing with complex natural resource systems. The case in tropical America shows how trust-building, communication, and understanding of multiple realities are crucial to bridge different agendas for sustainable development. All of the case studies are balanced and insightfully written, illustrating many of the points made in Part 1. However, in their desire to illustrate the complexity of the real world, the authors have somewhat over-loaded the volume with text boxes, framework figures, and detailed models. This approach may repel some of the readers that would most benefit from the volume.

In Part 3, the authors emphasize the need to connect research with management. They claim that research should be integrated with management such that research meets management needs and management helps answer relevant research questions. In addition, they advocate research that takes place not only within disciplines, but also at the interface between disciplines, what I would call trans-disciplinary research. In the last chapter, they argue for a new paradigm of research and management based on participation and the synchronization of top-down (centralized) and bottom-up (community-driven) approaches. They suggest that scientific rewards be linked to improved performance of the system, rather than to the number of journal articles produced. However, failures in natural resource management should not be excluded from the scientific debate. Because the uncertainties and complexities require that there is continuous learning through trial and error, analyzing mistakes and successes should be equally rewarding. Therefore, the authors argue that indicators of natural resource system performance should reflect adaptability and a capacity for learning, rather than, for example, increased yields or adoption of new technology.

Overall, this book is a welcome contribution to the field of sustainable development. The authors' extensive experience from the research-management continuum, as well as the conservationdevelopment continuum, gives credibility and detail to the lessons learned. I believe that both scientists and managers can find inspiration and enlightenment from this book. Having followed development and conservation projects in Sweden, I would expand the audience to managers and scientists based in high-income countries. While no management recipe suits every situation, many of the pitfalls and keys to success described apply world wide.

\section{Book Information}

Sayer, J. A., and B. M. Campbell. 2004. The Science of Sustainable Development. Local Livelihoods and the Global Environment. Cambridge University Press, Cambridge, UK. 288 pp., paperback, U.S. \$40.00, ISBN 0-521-53456-9.

Responses to this article can be read online at:

http://www.ecologyandsociety.org/vollo/iss $2 /$ art $21 /$ responses/

\section{LITERATURE CITED}

Folke, C., T. Hahn, J. Norberg, and P. Olsson. 2005. Adaptive governance of social-ecological systems. Annual Review of Environment and Resources 30:441-473.

Sayer, J. A., and B. M. Campbell. 2004. The Science of Sustainable Development. Local Livelihoods and the Global Environment. Cambridge University Press, Cambridge, UK. 